\title{
Traduciendo a Epicteto
}

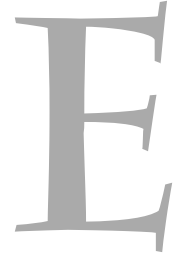

l maestro da siempre la clase al caer de la tarde, frente a un jardín sin flores. La misma todos lo días, con los mismos alumnos, aunque vayan cambiando de nombre, año tras año. Una vez son Arturo y Jesús, otra vez son Pablo y Henry, y Carlos y Eduardo.

Todos lo mismo: con diez y seis o dieciséis años, y con los mismos ensueños y los mismos entusiasmos.

El aula se mantiene idéntica a despecho del tiempo; unos bancones viejos y gruesos, un tablero un tanto desnegrido. Empero, a pesar de la humildad del recinto, y de que son muy pocos alumnos, la clase tiene ambiente inconfundible. Los muchachos están perfectamente atentos a la secreta instrucción que allí se da.

Es la clase de la lengua de Homero. El maestro, después de un cuarto de hora de gramática pasa a la traducción, que es la finalidad de estudio. En la clase se han traducido todos los principales autores: Homero, Sófocles, Eurípides, Platón, Demóstenes, Luciano, Epicteto, San Juan, Crisóstomo.

Cuando se traduce, el viejo maestro se levanta los anteojos sobre la frente. Y todavía se entusiasma, como cuando estaba joven, como cuando era la primera vez. Primero, él mismo lee con entonación el trozo, luego lo repite el alumno, después se vierte y por último se vuelve a leer como para despedirse del verso o del pe- riodo. Cuando se comenta a Demóstenes el alumno debe repetir con voz oratoria el pasaje como si estuviera delante de Esquines y de los jueces. Después de las grandes páginas hay ordinariamente perorata del preceptor. «Sepan que estamos traduciendo lo más bello de la literatura griega, que es la mejor del mundo. De aquí para arriba no queda nada humanamente.....» Esta lengua maravillosa para nada determinado sirve, y sin embargo es indispensable para la cultura. Sin ella, la humanidades serían una palabra vacía. Yo pienso que tenía mucha razón el pedagogo alemán que aconsejaba empezar por griego más bien que por latín los estudios clásicos.

«Ustedes saben muy bien que no traducimos esto sólo para conocer la trama de esta tragedia, o de esta tesis, o de esta discusión». Eso sería utilitarismo, y no humanismo. Lo traducimos para la formación, para obtener aquello que llevarán durante toda la vida, aquello que queda cuando lo hayan olvidado todo. Algo que es desarrollo, equilibrio, plenitud de todas la facultades, madurez en una sola palabra.

«Con esto podrán ustedes jerarquizar sus ideas, trabarlas unas con otras, empalmar cada conocimiento con lo que ya se sabe y con lo que está por saberse. Al fin de estos estudios habrán logrado algo que no se alcanza estudiando ciencias o matemáticas: una orientación intelectual sobre ejes fijos, ponderación personal. Habrán echado a su bagaje para toda la vida, en cuanto la alforja tenía capacidad, una gran medida de sensatez». 
Un día, luego que el maestro terminó su encomio de la lengua, un alumno levantó la mano para preguntar, y preguntó:

- De modo, Reverendo Maestro, que no hay nada por encima del griego?

- Sí: hay una cosa, respondió el profesor: y es el dolor... Y encima del dolor, está el amor; y encima del amor, está el conocerse a sí mismo, y despreciarse, y conocer a Dios, y amarlo... Eso sí, está por encima de todo: de toda armonía, y de toda luz, y de toda aspiración...

- De modo, Maestro - insistió el alumno -, que más vale conocernos a nosotros mismos, y despreciarnos, y conocer a Dios para amarlo, que todo lo que dice aquí nuestro divino Epicteto?

- El maestro se quitó los anteojos y los colocó entre las hojas del libro abierto.

Esa pregunta de su discípulo era la que a él continuamente atormentaba, la que ponía una sutil fuente de tristeza en su espíritu.

- Así es, amigo mío, más que toda belleza intelectual está el «conócete a ti mismo» y sobre todo, el primer precepto que dice:

“Amarás a tu Dios de todo corazón». Pero por encima de las palabras y de los sentimientos, están las obras: y la suprema de ellas, es la de morir por Dios y por Cristo».

Esa es la suprema belleza. Busquen ustedes, mis discípulos, la ocasión de morir por lo divino. Un bello morir hermosea toda la vida, vivir y morir. Vivir y morir por Cristo sí está por encima de leer a Epicteto.

- Y ¿́cómo ponernos en la ocasión próxima de morir por Cristo?- interrogó de nuevo el joven.

Esta vez el humilde maestro de griego, bajó la cabeza ruborizado.

Rafael García-Herreros Mayo de 1945

Tomado del documento La Aventura Humanista del archivo del minuto de Dios.

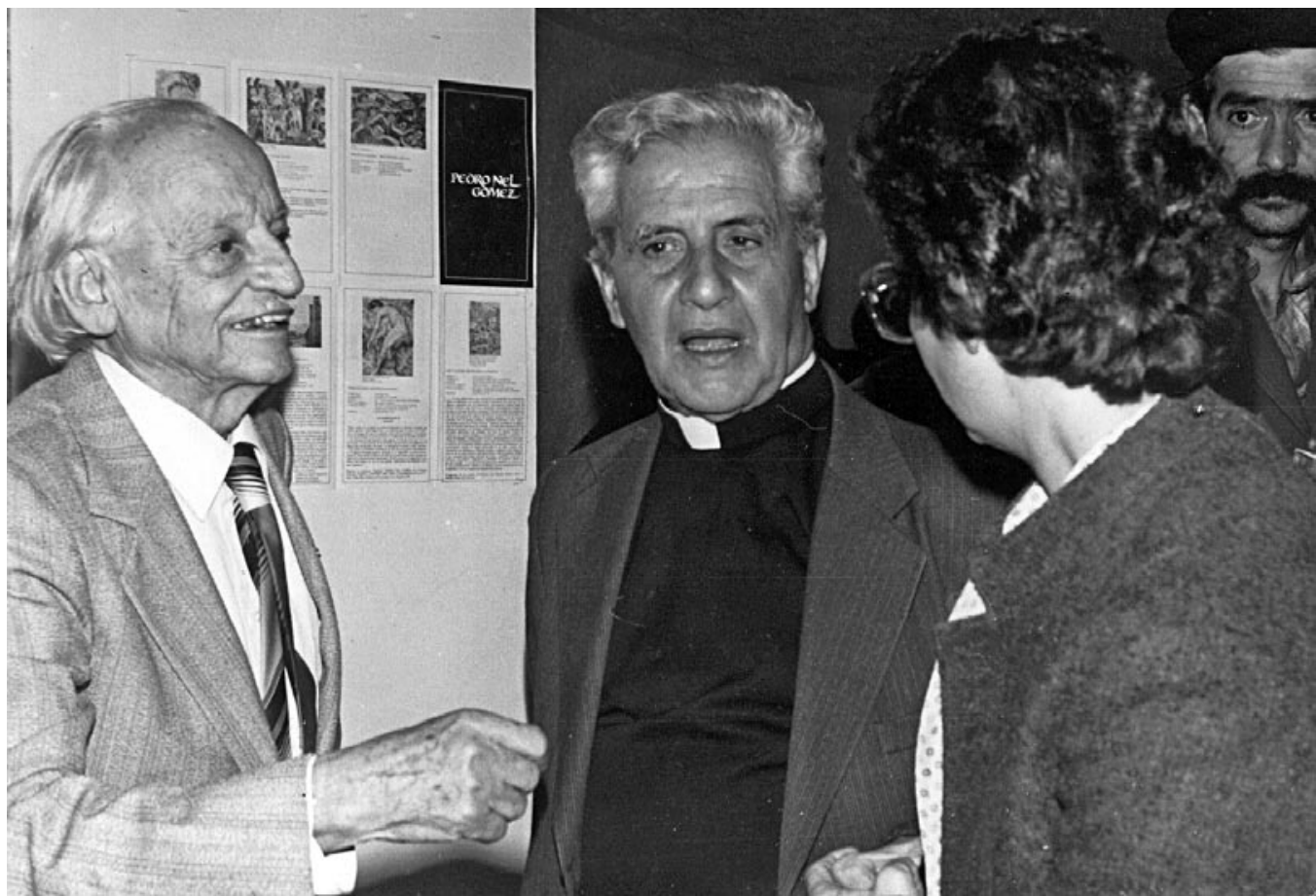

El Padre Rafael García-Herreros, participó activamente en la vida cultural del Museo de Arte Contemporáneo. 